\title{
Pengaruh Pemberian Mikoriza Vesikula Arbuskula (MVA) Campuran terhadap Kemunculan Penyakit Layu Fusarium pada Tanaman Melon (Cucumis melo L.)
}

\author{
Najmah Farhati ${ }^{1}$, Purnomowati ${ }^{1}$, Uki Dwiputranto ${ }^{1}$ \\ ${ }^{1}$ Fakultas Biologi Universitas Jenderal Soedirman Purwokerto \\ E-mail: najmahfarhati@gmail.com
}

\begin{abstract}
Melon (Cucumis melo L.) has economic potential to be cultivated because the fruit contains protein, fat, carbohydrate, calcium, phosphor, fiber, iron, vitamin $A$, vitamin $B 1$, vitamin $B 2$, vitamin $C$, and niacin. Fusarium wilt caused by Fusarium oxysporum will decrease melon crop production. One of controlling method to Fusarium wilt diseases on melon plants which safe for environtmental by using biological control. One of microorganisms which can be biological control agent is Vesicular Arbuscular Mycorrhiza (VAM). This research use experimental method with a Completely Randomized Design (CRD). The experimental treatment consists of two types of treatment which combine 5 doses of VAM mixture ( $0 \mathrm{~g} /$ plant, $10 \mathrm{~g} /$ plant, $12,5 \mathrm{~g} / \mathrm{plant}, 15 \mathrm{~g} / \mathrm{plant}, 17,5 \mathrm{~g} / \mathrm{plant}$ ) and two inoculation method VAM is inoculated when seeds are planted and inoculation when the seedlings are replanted. Each treatment was repeated 3 times and each unit consist of three plant, so there are 30 units of experiments or 90 plants. The main variabels are observed consist of the incubation periode of the disease and the intensity of fusarium wilt and the supporting variabels consist of $\mathrm{pH}$, temperature, humidity, and the scale of infection. The mixed MVA $15 \mathrm{~g} / \mathrm{plant}$ dosage inoculated when seeds are planted and $15 \mathrm{~g} /$ plant dosage inoculated when the seedlings are replanted is the most effective to suppress incubation period of Fusarium wilt disease.
\end{abstract}

Key words: Cucumis melo L., F usarium .oxysporum, VAM

\begin{abstract}
Abstrak
Tanaman melon (Cucumis melo) memiliki potensi ekonomi untuk dibudidayakan karena buahnya mengandung protein, lemak, karbohidrat, kalsium, fosfor, serat, besi, vitamin A, vitamin B1, vitamin B2, vitamin C, dan niacin. Penyakit layu fusarium yang disebabkan oleh Fusarium oxysporum menyebabkan produksi melon mengalami penurunan. Salah satu cara pengendalian penyakit layu fusarium pada tanaman melon yang ramah lingkungan adalah penggunaan musuh alami atau pengendalian secara hayati. Salah satu mikroorganisme yang dapat menjadi agen pengendali hayati adalah Mikoriza Vesikula Arbuskula (MVA). Metode yang digunakan adalah metode eksperimental dengan Rancangan Acak Lengkap (RAL) yang terdiri atas 5 dosis MVA campuran (0 g/tanaman, 10 $\mathrm{g} / \mathrm{tanaman}, 12,5 \mathrm{~g} / \mathrm{tanaman}, 15 \mathrm{~g} / \mathrm{tanaman}, 17,5 \mathrm{~g} / \mathrm{tanaman}$ ) dan 2 cara inokulasi yang dikombinasikan (inokulasi saat biji ditanam, inokulasi saat bibit dipindahtanamkan). Masing-masing perlakuan dilakukan 3 (tiga) kali ulangan dan setiap ulangan adalah tiga tanaman, sehingga jumlah seluruhnya ada 30 unit percobaan atau 90 tanaman. Parameter yang diamati yaitu masa inkubasi penyakit dan munculnya penyakit layu fusarium pada tanaman melon dan parameter pendukung yaitu $\mathrm{pH}$, temperatur, kelembapan, dan derajat infeksi. Dosis $15 \mathrm{~g} / \operatorname{tanaman}$ saat biji di tanam dan dosis $15 \mathrm{~g} /$ tanaman saat bibit dipindahtanamkan merupakan dosis yang paling efektif untuk memperpanjang masa inkubasi penyakit layu fusarium pada tanaman melon.
\end{abstract}

Kata kunci: Melon, Fusarium oxysporum, MVA

\section{Pendahuluan}

Tanaman melon (Cucumis melo) merupakan tanaman semusim yang banyak dibudidayakan di Indonesia. Upaya pengendalian penyakit layu fusarium pada tanaman melon yang banyak dilakukan antara lain dengan pengaturan pola tanam, penggunaan varietas tahan, rotasi tanaman dan penggunaan fungisida, namun demikian upaya tersebut kurang memberikan hasil yang memuaskan. Penggunaan fungisida selain harganya mahal berpotensi pula menimbulkan dampak negatif, seperti tercemarnya lingkungan oleh residu senyawa kimia tersebut. Alternatif lain yang bisa digunakan untuk mengendalikan penyakit layu fusarium pada tanaman melon adalah dengan pemanfaatan Mikoriza Vesikula Arbuskula (MVA) (Rozy et al., 2004).
Talanca \& Adnan (2005) menyatakan bahwa ketahanan tanaman terhadap patogen akibat infeksi mikoriza disebabkan oleh adanya bahan yang dihasilkan oleh sel korteks tanaman inang yang bertindak sebagai antibiotik seperti fenol, kuinon, dan berbagai fitoaleksin yang dapat menghambat infeksi dan penyebaran patogen. Selain itu, infeksi jamur mikoriza juga dapat membantu merangsang terbentuknya isoflavonoid pada akar tanaman (Mosse, 1981).

Penggunaan MVA sebagai pengendali hayati penyakit tumbuhan telah banyak dilakukan. Keberhasilan infeksi MVA pada tanaman tidak hanya ditentukan dari dosis inokulasinya saja, tetapi juga oleh cara inokulasinya (Basuki, 2003). Menurut Fakuara (1988), terdapat dua cara inokulasi MVA yaitu inokulasi saat biji ditanam dan saat bibit ditanamkan. Dosis yang sesuai dengan cara inokulasi yang tepat akan 
menghasilkan infeksi MVA yang baik. Penelitian sebelumnya tentang pengendalian penyakit layu fusarium pada tanaman semangka didapatkan hasil bahwa dosis $12,5 \mathrm{~g} /$ tanaman adalah dosis yang paling baik untuk memperpanjang masa inkubasi penyakit layu fusarium pada tanaman semangka. Penelitian ini akan menggunakan inokulum MVA campuran yang terdiri dari Glomus clarum dan Gigaspora sp. dengan dosis dan cara inokulasi yang berbeda untuk mengendalikan penyakit layu fusarium pada tanaman melon.

Berdasarkan uraian diatas didapatkan rumusan masalah sebagai berikut, apakah pemberian MVA campuran dengan dosis dan cara inokulasi yang berbeda berpengaruh terhadap munculnya penyakit layu fusarium pada tanaman melon serta dosis dan cara inokulasi MVA campuran manakah yang paling efektif untuk mengendalikan penyakit layu fusarium pada tanaman melon. Tujuan penelitian ini adalah 1) Pengaruh dosis dan cara inokulasi MVA campuran terhadap munculnya penyakit layu fusarium pada tanaman melon., 2) Dosis dan cara inokulasi MVA campuran yang paling efektif untuk mengendalikan penyakit layu fusarium pada tanaman melon.

\section{Metode}

Bahan yang digunakan dalam penelitian adalah benih melon (Cucumis melo) Amanta F1, inokulum MVA campuran (Glomus clarum dan Gigaspora sp.), isolat Fusarium oxysporum, medium Potato Dextrose Agar (PDA), dedak, alkohol $70 \%$, tanah steril, air, akuades, aluminium foil, kapas, korek api, dan spiritus sedangkan alatalat yang digunakan dalam penelitian ini antara lain adalah cawan petri, labu Erlenmeyer, autoklaf, drum sterilisasi, beaker glass, Laminar Air Flow (LAF), jarum ose, bor gabus, termometer, thermohygrometer, soil tester, pembakar spiritus, kertas label, pensil, timbangan, polibag ukuran 30 $\mathrm{cm} \times 30 \mathrm{~cm}(3 \mathrm{~kg})$, gelas ukur, botol selai, hand sprayer, kompor gas, panci, ember, nampan, plastik, dan kamera. Penelitian dilaksanakan di Green house dan Laboratorium Mikologi dan Fitopatologi, Fakultas Biologi Universitas Jenderal Soedirman, Purwokerto.

Metode penelitian yang digunakan yaitu metode eksperimental menggunakan Rancangan Acak Lengkap (RAL) dengan perlakuan 5 dosis MVA campuran dan 2 cara inokulasi, ulangan masing-masing perlakuan sebanyak 3 kali. Setiap ulangan terdapat 3 tanaman sehingga jumlah seluruhnya berjumlah 30 unit percobaan atau 90 tanaman.

Pembuatan Media Potato Dextrose Agar (PDA) dengan cara mengambil hasil ekstrak kentang yang telah dihomogenkan kemudian disterilisasi menggunakan autoklaf pada suhu 121 ${ }^{\circ} \mathrm{C}$ dengan tekanan $2 \mathrm{~atm}$ selama 15 menit. Uji patogenitas dilakukan dengan cara melihat gejala layu yang muncul pada tanaman melon yang berumur 21 HST melalui aplikasi tanah dalam nampan plastik dan diinkubasi selama $21 \mathrm{HSI}$ (Harizon, 2009). Inokulum MVA ditimbang sesuai dosis dan diinokulasi ke tanah steril pada polybag melalui 2 aplikasi yaitu Inokulasi MVA campuran saat biji ditanam dan Inokulasi MVA campuran saat bibit ditanam. Inokulasi dilakukan saat biji ditanam langsung dilakukan dengan cara meletakkan inokulum MVA campuran sedalam \pm 3 $\mathrm{cm}$ di bawah biji tanaman melon kemudian biji ditutup tanah. Inokulum MVA campuran diinokulasikan saat bibit melon dipindahtanamkan ke media tanam dalam polibag. Inokulasi dilakukan dengan cara meletakkan inokulum MVA campuran dengan jarak $\pm 3 \mathrm{~cm}$ di bawah akar tanaman melon (Ertanti, 2011). Pengamatan Morfologi Spora MVA dilakukan mengacu pada Petrus et al. (2013), dengan metode saring bertingkat yang berukuran $300 \mu \mathrm{m}, 150 \mu \mathrm{m}$, dan $45 \mu \mathrm{m}$ secara berurutan. Inokulasi jamur $F$. oxysporum dilakukan setelah tanaman berumur 30 HSI. Menurut Purnomowati (1996), inokulum jamur yang diinokulasikan sebanyak $10 \mathrm{~g}$ tiap 3 $\mathrm{kg}$ tanah. Pengamatan masa inkubasi dilakukan 1 HSI selama 21 hari dengan cara mencatat waktu (hari) munculnya gejala pertama layu fusarium pada setiap perlakuan. Penghitungan intensitas penyakit dilakukan 21 hari setelah inokulasi $F$. oxysporum dengan menggunakan rumus Soenartiningsih (1997) :

$\mathrm{I}=\frac{\Sigma(\mathrm{nxv})}{\mathrm{ZxN}} \times 100 \%$

Keterangan :

$\mathrm{I}=$ intensitas penyakit

$\mathrm{n}=$ jumlah tanaman yang terserang tiap kategori

$v$ = nilai kategori pada setiap tanaman yang terserang

$Z=$ nilai kategori yang tertinggi

$\mathrm{N}=$ jumlah tanaman yang diamati

Menurut Rahayuniati dan Endang (2009), untuk menghitung rumus intensitas penyakit maka tanaman yang terserang patogen dibagi dalam 5 kategori, yaitu :

0 = tidak ada gejala

1 = gejala daun menguning $25 \%$

2 = gejala daun menguning $>25 \%-50 \%$

$3=$ gejala daun menguning $>50 \%-75 \%$

$4=$ gejala daun menguning $>75 \%-100 \%$

Menurut Mardatin (2007), Pengamatan derajat infeksi dilakukan di akhir penelitian dengan metode clearing dan staining. Pengamatan derajat infeksi MVA dihitung dengan rumus :

Derajat Infeksi $=\frac{\text { Jumlah akar } \text { yang terinfeksi }}{\text { Jumlah akar yang diamati }} \times 100 \%$ 


\section{Hasil dan Pembahasan}

Berdasarkan hasil pengamatan terhadap rata-rata masa inkubasi penyakit layu fusarium pada tanaman melon yang diinokulasi MVA campuran dengan dosis dan cara inokulasi yang berbeda adalah 5,16-13,96 Hari Setelah Inokulasi (HSI). Menurut Seo \& Kim (2017), timbulnya gejala penyakit layu fusarium pada tanaman melon terlihat pada 3-20 Hari Setelah Inokulasi. Hasil Analisis Ragam menunjukkan bahwa dosis dan cara inokulasi MVA campuran berpengaruh sangat nyata terhadap masa inkubasi penyakit layu fusarium pada tanaman melon. Ketahanan tanaman terhadap patogen akibat infeksi mikoriza memiliki masa inkubasi yang lebih panjang. Hal ini disebabkan karena perlakuan tanaman tanpa diberi mikoriza panjang batangnya mengalami penurunan yang disebabkan karena penyerapan dan transportasi air terganggu. Hal ini sesuai dengan pernyataan Wahyu et al. (2013), bahwa tanaman akan kehilangan air yang lebih besar dibandingkan dengan air yang masuk menyebabkan sel-sel daun lambat laun kehilangan tekanan turgor. Lebih lanjut Mosse (1981), menyatakan tanaman yang terinfeksi mikoriza lebih tahan terhadap patogen dibandingkan dengan tanpa mikoriza.

Tabel 1. Uji BNT Pengaruh dosis dan cara inokulasi MVA campuran terhadap masa inkubasi penyakit layu fusarium pada tanaman melon.

\begin{tabular}{rlc}
\hline No & Perlakuan & Rata-rata (hari) \\
\hline 1 & M0BJ (0 g/tanaman biji ditanam) & $5,73 \mathrm{~g}$ \\
2 & M0BT (0 g/tanaman bibit dipindahtanamkan) & $5,16 \mathrm{~g}$ \\
3 & M1BJ (10 g/tanaman biji ditanam $)$ & $6,96 \mathrm{f}$ \\
4 & M1BT (10 g/tanaman bibit dipindahtanamkan) & $7,73 \mathrm{e}$ \\
5 & M2BJ (12,5 g/tanaman biji ditanam) & $10,4 \mathrm{c}$ \\
6 & M2BT (12,5 g/tanaman bibit dipindahtanamkan) & $9,16 \mathrm{~d}$ \\
7 & M3BJ (15 g/tanaman biji ditanam) & $13,93 \mathrm{a}$ \\
8 & M3BT (15 g/tanaman bibit dipindahtanamkan) & $13,96 \mathrm{a}$ \\
9 & M4BJ (17,5 g/tanaman biji ditanam) & $11,53 \mathrm{~b}$ \\
10 & M4BT (17,5 g/tanaman bibit dipindahtanamkan) & $11,16 \mathrm{~b}$ \\
\hline
\end{tabular}

Keterangan :

Angka yang diikuti oleh huruf yang sama dalam satu kolom tidak berbeda nyata pada BNT 5\%.

Tabel 1. menunjukkan bahwa dosis dan cara inokulasi MVA campuran yang paling efektif untuk memperpanjang masa inkubasi penyakit layu fusarium pada tanaman melon adalah perlakuan M3BT (inokulasi MVA campuran 15 $\mathrm{g} / \mathrm{tanaman}$ saat bibit dipindahtanamkan ke polibag) dan M3BJ (inokulasi MVA campuran 15 g/tanaman saat biji ditanam). Menurut Gunawan (1993), pemberian dosis inokulum yang semakin banyak maka spora yang hidup dan besinggungan (kontak) dengan perakaran tanaman semakin banyak, sehingga meningkatkan laju infeksi mikoriza.

Hasil Analisis Ragam pada pengamatan intensitas penyakit layu fusarium pada tanaman melon menunjukkan bahwa dosis dan cara inokulasi MVA campuran tidak berpengaruh nyata terhadap intensitas penyakit layu fusarium pada tanaman melon. Hal ini dimungkinkan memiliki kaitan dengan derajat infeksi. Hasil derajat MVA campuran pada tanaman melon tergolong sedang dengan rata-rata derajat infeksi $30,99 \%$ sehingga kurang memberikan pengaruh terhadap tanaman.
Hal ini sesuai dengan pernyataan Setiadi (1995), bahwa tidak semua jenis tanaman memberikan respon positif terhadap aplikasi MVA, selain ditentukan oleh tingkat efektivitas isolat, nutrisi substrat yang digunakan dan ketergantungan tanaman terhadap mikoriza. Pemberian mikoriza ke dalam tanah menentukan banyaknya akar yang terinfeksi. Menurut Santosa (1989), peran mikoriza erat kaitannya dengan ketersediaan unsur $\mathrm{P}$ bagi tanaman. Konsentrasi $\mathrm{P}$ yang tinggi menyebabkan tanaman bermikoriza menyerap $P$ dalam jumlah yang lebih banyak. Lebih lanjut Brundrett et al., (1996), menyatakan derajat infeksi di bawah $70 \%$ kurang optimal dan belum cukup memberikan pengaruh terhadap tanaman. Menurut Brundrett et al., (1996), kriteria efektifitas derajat infeksi MVA dibagi menjadi 5 kriteria yakni $0 \%-5 \%$ (sangat rendah), $>5 \%-25 \%$ (rendah), $>25 \%-50 \%$ (sedang), $>50 \%-70 \%$ (tinggi), dan $>70 \%-100 \%$ (sangat tinggi). 
Tabel 2. Uji BNT Pengaruh dosis dan cara inokulasi MVA campuran terhadap derajat infeksi penyakit layu fusarium pada tanaman melon.

\begin{tabular}{rlc}
\hline No & Perlakuan & Rata-rata (hari) \\
\hline 1 & M0BJ (0 g/tanaman biji ditanam) & $4,05 \mathrm{e}$ \\
2 & M0BT (0 g/tanaman bibit dipindahtanamkan) & $4,05 \mathrm{e}$ \\
3 & M1BJ (10 g/tanaman biji ditanam) & $26,29 \mathrm{~d}$ \\
4 & M1BT (10 g/tanaman bibit dipindahtanamkan) & $28 \mathrm{~d}$ \\
5 & M2BJ (12,5 g/tanaman biji ditanam) & $33,09 \mathrm{~cd}$ \\
6 & M2BT (12,5 g/tanaman bibit dipindahtanamkan) & $35,91 \mathrm{bc}$ \\
7 & M3BJ (15 g/tanaman biji ditanam) & $41,27 \mathrm{ab}$ \\
8 & M3BT (15 g/tanaman bibit dipindahtanamkan) & $45,26 \mathrm{a}$ \\
9 & M4BJ (17,5 g/tanaman biji ditanam) & $44,66 \mathrm{a}$ \\
10 & M4BT (17,5 g/tanaman bibit dipindahtanamkan) & $47,26 \mathrm{a}$ \\
\hline
\end{tabular}

Keterangan :

Angka yang diikuti oleh huruf yang sama dalam satu kolom tidak berbeda nyata pada BNT 5\%.

Tabel 2 menunjukkan bahwa perlakuan M1BJ merupakan perlakuan dengan derajat infeksi paling rendah tidak berbeda nyata dengan perlakuan M1BT dan M2BJ tetapi berbeda nyata dengan perlakuan M2BT. Besarnya derajat infeksi pada akar digunakan untuk mengetahui efektivitas dari mikoriza dalam menginfeksi akar. Berdasarkan hasil pengamatan derajat infeksi MVA terdiri dari Gigaspora sp. dan Glomus clarum menunjukkan adanya arbuskula dan vesikula. Menurut Simanungkalit (2003), jamur ini dicirikan dengan adanya struktur arbuskula, vesikula pada membran sel tanaman, hifa eksternal dan hifa internal.

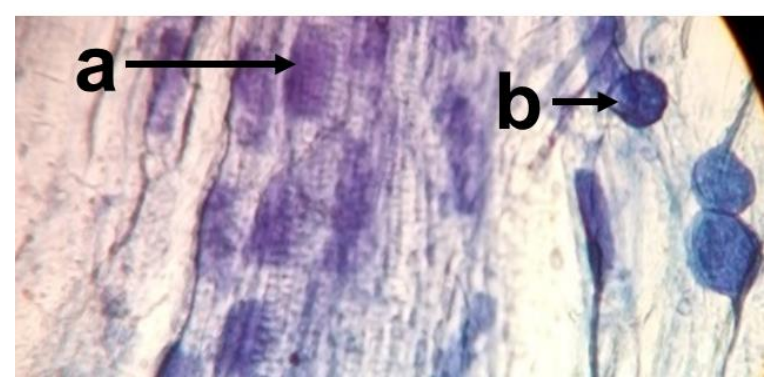

Gambar 1. Akar tanaman melon yang terinfeksi MVA campuran ( $a=$ Arbuskula, $b=$ Vesikula)

Kondisi lingkungan di green house selama penelitian berada pada kisaran temperatur 26-30 ${ }^{\circ} \mathrm{C}$, kelembapan pada kisaran $28-80 \%$ dan $\mathrm{pH}$ tanah berkisar 6-6,4. Kondisi tersebut mendukung pertumbuhan tanaman melon maupun MVA. Menurut Samadi (2007), keasaman $(\mathrm{pH})$ tanah untuk pertumbuhan tanaman melon antara 6,06,8. Lebih lanjut Koentjoro (2012), menyatakan kelembapan untuk pertumbuhan tanaman melon berkisar $70-80 \%$, dan suhu yang optimum untuk pertumbuhan tanaman melon berkisar $20-30^{\circ} \mathrm{C}$. Menurut Suhardi (1987), temperatur optimum untuk pertumbuhan jamur MVA berkisar antara $30-35^{\circ} \mathrm{C}$. Lebih lanjut Gunawan (1993) menyatakan bahwa jamur MVA membutuhkan kelembapan antara $80 \%-95 \%$ dan $\mathrm{pH}$ optimum untuk pertumbuhan jamur MVA adalah 3-7.

\section{Simpulan dan Saran \\ Simpulan}

Berdasarkan hasil penelitian dapat disimpulkan bahwa (1) Dosis dan cara inokulasi MVA campuran belum mampu mengendalikan penyakit layu fusarium pada tanaman melon, namun dapat memperpanjang masa inkubasi penyakit layu fusarium pada tanaman melon dan (2) Dosis MVA campuran $15 \mathrm{~g} /$ tanaman pada saat biji ditanam dan dosis $15 \mathrm{~g} /$ tanaman pada saat bibit dipindahtanamkan merupakan dosis yang paling efektif untuk memperpanjang masa inkubasi penyakit layu fusarium pada tanaman melon.

\section{Saran}

Guna mengendalikan kemunculan penyakit layu fusarium pada tanaman melon dengan penambahan mikoriza vesikula arbuskula (MVA) campuran sebaiknya dengan dosis $15 \mathrm{~g} /$ tanaman, karena berdasarkan analisis ragam terhadap masa inkubasi penyakit diperoleh hasil uji BNT pada perlakuan M3BT (dosis $15 \mathrm{~g} /$ tanaman bibit dipindahtanamkan) merupakan perlakuan dengan masa inkubasi paling lama 13,96 hari dan perlakuan M3BJ (dosis $15 \mathrm{~g} /$ tanaman bii ditanam) dengan masa inkubasi 13,93 hari. 


\section{Daftar Referensi}

Basuki, A. Y., 2003. Aplikasi Mikoriza Vesikula Arbuskula (MVA) Campuran Untuk Menekan Penyakit Layu Fusarium Pada Tanaman Tomat (Lycopersion Esculentum L.). Skripsi (Tidak Dipublikasikan). Purwokerto: Fakultas Biologi Universitas Jenderal Soedirman.

Brundrett, M., Bougher, N., Dell, B., Grove, T., Malajczuk, N., 1996. Working With Mychorrizas In Forestry and Agriculture. ACIAR Monograph. Canberra: Australia.

Ertanti, A., 2011. Pertumbuhan Tanaman Semangka (Citrullus vulgaris) pada Tanah Masam yang Diinokulasi Mikoriza Vesikula Arbuskula (MVA) Campuran dengan Cara Inokulasi dan Dosis Berbeda. Skripsi. Purwokerto: Fakultas Biologi Universitas Jenderal Soedirman.

Fakuara, M. Y., 1988. Mikoriza, Teori dan Kegunaan Dalam Praktek. Pusat Antar Universitas. Institut Pertanian Bogor, Bogor.

Gunawan, A.W., 1993. Mikoriza Arbuskula. Bahan Pengajaran Pusat Antar Universitas IIImu Hayati. Bogor: Institut Pertanian Bogor.

Harizon., 2009. Biofungisida Berbahan Aktif Eusiderin I untuk Pengendalian Layu Fusarium pada Tomat. Biospecies, 2(1), pp.30-41.

Koentjoro, Y., 2012. Efektifitas Model Pemangkasan dan Pemberian Pupuk Majemuk Terhadap Tanaman Melon (Cucumis melo L.). Berkala IImiah Agroteknologi Plumula. 1, pp.9-17.

Mardatin, N. F., 2007. Teknik Bekerja dengan Cendawan Mikoriza Arbuskula. Bogor: Kongres Nasional Mikoriza Indonesia II.

Mosse, B., 1981. Vesicular-Arbuscular Mycorrhizal Research for Tropical Agriculture. Res, Bull.

Petrus, Burhanuddin, \& Reine, S.W., 2013. Asosiasi Cendawan Mikoriza Arbuskula pada Ketapang (Terminalia catappa). Laporan Hasil Penelitian. Pontianak: Fakultas Kehutanan Universitas Tnjungpura.

Purnomowati., 1996. Inokulum Mikoriza Vesikula Arbuskula (MVA) Glomus sp. dan G. margarita sebagai Upaya untuk Menekan Penyakit Busuk Batang Sclerotium pada Tanaman Kedelai (Glycine max (L) merr). Purwokerto: Laporan Hasil Penelitian Fakultas Biologi Universitas Jenderal Soedirman.
Rahayuniati, R.F. \& Endang, M., 2009. Pengendalian Penyakit Layu Fusarium Tomat: Aplikasi Abu Bahan Organik dan Jamur Antagonis. Jurnal Pembangunan Pedesaan, 9(1), pp.26-34.

Rozy, F., E. Liestiany \& Maftuhah., 2004. Kemampuan Mikoriza Mengendalikan Serangan Rhizoctonia solani Kuhn pada Kedelai. Agroscientiae, 2 (11).

Samadi, B., 2007. Melon: Usaha Tani dan Penanganan Pasca Panen. Yogyakarta: Kanisus.

Santosa, D. A., 1989. Teknik dan Metode Penelitian MVA. Laborotarium Biologi tanah Jurusan Tanah Fakultas Pertanian IPB. Bogor.

Seo, Y. \& Kim, Y. H., 2017. Potential Reasons for Prevalence of Fusarium Wilt in Oriental Melon in Korea. The Plant Pathology Journal. 33(3), pp.249-263.

Setiadi, Y. 1995. Arbuscular Mycorrhizal Inoculum Production. Dalam Prosiding: Teknologi Produksi dan Pemanfaatan Inokulan EndoEktomikoriza untuk Pertanian, Perkebunan dan Kehutanan. Asosiasi Mikoriza Indonesia-Jawa Barat. ISBN 979-98255-04.

Simanungkalit, R.D.M., 2003. Teknologi Jamur Mikoriza Arbuskular: Produksi inokulan dan pengawasan mutunya. Program dan Abstrak Seminar dan Pameran: Teknologi Produksi dan Pemanfaatan Inokulan Endomikoriza untuk Pertanian, Perkebunan dan Kehutanan, 11.

Soenartiningsih., 1997. Pengaruh Cendawan Mikoriza Vesikular-Arbuskular terhadap Intensitas Penyakit Utama pada Tanaman Jagung. Seminar Nasional Biologi XV. pp.1161-1165.

Suhardi., 1987. Pemanfaatan Mikoriza bagi Pengembangan Pertanian dan kehutanan di Indonesia. Makalah Seminar Bioteknologi Indonesia 17-19 Februari 1987. Yogyakarta: Fakultas Kehutanan UGM.

Talanca, A. H \& A. M. Adnan., 2005. Mikoriza Dan Manfaatnya Pada Tanaman. Prosiding Seminar IImiah dan Pertemuan Tahunan PEI dan PFI XVI Komda sul-sel. Balai Penelitian Tanaman Serealia, Sulawesi Selatan.

Wahyu, E. R., Kristanti, I. P., \& Sri, N., 2013. Pengaruh Glomus fasciculatum pada Pertumbuhan Vegetatif Kedelai yang Terinfeksi Sclerotium rolfsii. Jurnal Sains dan Seni Pomits, 2 (2): 64-68. 